\title{
O Museu da Lingua Portuguesa e o discurso da norma
}

The Museu da Língua Portuguesa and the standard discourse

\author{
Heloisa Mara Mendes \\ Maura de Freitas Rocha
}

Universidade Federal de Uberlândia, Uberlândia, MG, Brasil

\begin{abstract}
Resumo: Este trabalho filia-se à perspectiva teórica da Sociolinguística Variacionista e tem o objetivo de problematizar as noções de "erro" e norma mobilizadas em Erros nossos de cada dia, uma das instalações de Menas o certo do errado, o errado do certo, sexta exposição temporária do Museu da Língua Portuguesa. Do ponto de vista que adotamos para análise, a representação que o museu faz do que seja variação linguística é equivocada e parece assentar-se em uma perspectiva que julga os fatos linguísticos como corretos e incorretos a partir do que se diz sobre a língua nos manuais de gramática normativa.
\end{abstract}

Palavras-chave: Sociolinguística. Museu da Língua Portuguesa. Norma. Variação.

Abstract: This work is linked to the Variationist Sociolinguistics theoretical perspective and aims to debate the "mistake" notions and linguistics standard mobilized into Erros nossos de cada dia, one of the facilities of Menas o certo do errado, o errado do certo, sixth temporary exposition of the Museu da Língua Portuguesa. From the perspective we adopt to the analysis, the representation that the museum does about what is linguistic variation is mistaken and seems to support itself under a perspective that judges the linguistic facts as correct and incorrect based on what is said about the language in the standard grammar guides.

Keywords: Sociolinguistcs. Museu da Língua Portuguesa. Standard. Variation. 


\section{Heloisa Mara \\ Mendes}

Maura de

Freitas Rocha

\section{Introdução}

Neste trabalho, analisamos, a partir da perspectiva teórica da Sociolinguística Variacionista (doravante Sociolinguística), os fatos linguísticos e os comentários apresentados em Erros nossos de cada dia, uma das instalações de Menas o certo do errado, o errado do certo, sexta mostra a ocupar o espaço das exposições temporárias do Museu da Língua Portuguesa, localizado na cidade de São Paulo, SP, Brasil, e procuramos problematizar as noções de "erro" e norma linguística mobilizadas nessa instalação.

Em nossas análises, partimos da hipótese de que, no museu, há uma "exibição" de fatos de variação linguística, entre outras coisas, sob o pretexto de que nesse espaço não haveria preconceito linguístico ou de que esse seria um espaço mais "democrático" no tratamento de questões relacionadas ao português brasileiro; no entanto, a representação que a instituição faz do que seja variação é, no mínimo, equivocada, do ponto de vista que adotamos para análise, e parece assentar-se sobre uma perspectiva que julga os fatos linguísticos como corretos ou incorretos a partir do que se diz sobre a língua nos dicionários e manuais de gramática normativa, nos quais, comumente, a língua é tomada como a modalidade escrita da língua baseada em textos literários.

$\mathrm{Na}$ tentativa de alcançarmos os objetivos a que nos propomos, dividimos este trabalho em duas partes. Na primeira parte, discutimos a noção de norma e retomamos aspectos históricos elucidativos da constituição da norma dita culta do português empregado no Brasil. Na segunda parte, apresentamos nossas análises do corpus.

\section{Revisitando o conceito de norma e a constituição da norma culta do português brasileiro}

Em seu uso habitual ou mais próximo do senso comum, o termo norma designa uma variedade de língua que, em determinado período, se impõe e é imposta por todo um aparato prescritivo como o modelo por meio do qual todos os comportamentos linguísticos devem ser medidos. Trata-se da língua "correta", do "bom uso", definições que levam à classificação de todas as outras formas possíveis como "erros" ou "incorreções". Por representar a escolha de uma forma entre tantas possíveis, essa definição de norma é, de um ponto de vista estritamente linguístico, arbitrária.

A distinção feita pelo canadense Stanley Aléong (2001) entre normas explícitas e normas implícitas esclarece uma das formas de, 
ao mesmo tempo, compreender a existência de uma norma linguística sócio-historicamente dominante e a heterogeneidade das realizações linguísticas concretas:

\begin{abstract}
A norma explícita compreende esse conjunto de formas linguísticas que são objeto de uma tradição de elaboração, de codificação e de prescrição. Ela se constitui segundo processos sócio-históricos [...]. Codificada e consagrada num aparato de referência, essa norma é socialmente dominante no sentido de impor como o ideal a respeitar nas circunstâncias que pedem um uso refletido e monitorado da língua, isto é, nos usos oficiais, na imprensa escrita e audiovisual, no sistema de ensino e na administração pública. Quanto às normas implícitas, trata-se daquelas formas que, por serem raramente objeto de uma reflexão consciente ou de um esforço de codificação, nem por isso deixam de representar os usos concretos pelos quais o indivíduo se apresenta em sua sociedade imediata. (ALÉONG, 2001, p. 153).
\end{abstract}

Para tornar mais preciso o conceito de norma explícita, que se confunde com o conceito de norma padrão ou culta, Aléong (2001) identifica três componentes em toda norma desse tipo: i) um discurso da norma que classifica os fatos linguísticos em categorias de certo, errado, bom, mau, puro, padrão etc., é imperativo, autoritário e arbitrário; ii) um aparelho de referência que faz remissão a usuários revestidos de autoridade em matéria de linguagem, a academias, órgãos públicos, dicionários e gramáticas; e iii) a difusão e imposição em lugares estratégicos como a escola, a imprensa e a administração pública.

A nosso ver, a distinção empreendida por Aléong pode ser aproximada do pensamento de sociolinguistas na medida em que apreende a diversidade linguística como uma qualidade constitutiva da linguagem.

Na perspectiva de Alkmin (2001, p. 40, grifo nosso),

A variedade padrão de uma comunidade - também chamada de norma culta, ou língua culta - não é, como o senso comum faz crer, a língua por excelência, a língua original, posta em circulação, da qual os falantes se apropriam como podem ou são capazes. O que chamamos de variedade padrão é o resultado de uma atitude social ante a língua, que se traduz, de um lado, pela seleção de um 
dos modos de falar entre os vários existentes na comunidade e, de outro, pelo estabelecimento de um conjunto de normas que definem o modo 'correto' de falar.

Em sociedades como a nossa, a variedade culta ou padrão é a variedade linguística socialmente mais valorizada, possuidora de reconhecido prestígio e cujo uso normalmente é requerido em situações de

Heloisa Mara Mendes

Maura de Freitas Rocha interação comunicativa que exigem certa formalidade no que se refere tanto ao tratamento do tema quanto à relação estabelecida entre os interlocutores. No Brasil e em outras sociedades de tradição ocidental, a variedade padrão coincide com o modo de falar das classes sociais mais favorecidas e de determinadas regiões geográficas.

$\mathrm{Na}$ época em que se deu a associação entre uma variedade linguística e a escrita e, em seguida, entre essa variedade e a tradição gramatical, a distância entre a língua codificada na gramática e a realidade da variação já deveria ser enorme, visto que o saber clássico foi usado para dar valor e credibilidade às gramáticas dos falares “vulgares" e para expandir os léxicos fixados por meio de empréstimos gregos e latinos. Nesse contexto de legitimação do saber sobre a língua, a gramática normativa, na perspectiva de Gnerre (1998), é um elemento privilegiado: enquanto as ciências e a própria filosofia admitem a crítica e a refutação explícita de fases precedentes de produção intelectual, o mesmo não acontece com relação à norma padrão. Para esse autor,

\footnotetext{
[...] tal como na religião, nos valores morais e éticos, na norma linguística não aparece uma crítica explícita de fases anteriores. Pelo contrário, a impressão que é transmitida é de continuidade. 0 paralelo com a religião e a formalização da série de crenças e valores é útil: podemos pensar na distância, em termos de dogmas, práticas e crenças, entre o catolicismo do século XV e o atual. Ainda assim a ideia que é transmitida como característica central da igreja é a de continuidade e estabilidade. (GNERRE, 1998, p. 27-28).
}

No caso específico do Brasil, durante o período colonial, mas não somente, como procuraremos mostrar, a norma linguística da metrópole era o modelo de língua, algo que fica mais claro com relação à literatura. Sobre essa questão, Castilho $(1988$, p. 56) afirma que 
durante o período colonial nossos escritores produziram suas obras de olhos postos em Portugal. Não havia em nosso país público para eles, o analfabetismo era extensivo, as escolas eram poucas e apenas de nível elementar, pois o curso superior viria a dar seus primeiros passos apenas em 1808. Em Portugal iam buscar sua formação, e com isso sua linguagem representava o padrão de Lisboa ou de Coimbra.

No que diz respeito à língua literária no Brasil e sua relação com a norma culta, a escolha do "bom uso" da língua sempre foi calcada em motivos políticos e isso ainda vigora atualmente. Embora nosso país tenha sido "descoberto" em 1530, a pouca influência cultural exercida por Portugal fez com que continuássemos sendo um país rural de grande dimensão por aproximadamente trezentos anos. Foi a chegada da corte portuO Museu da Língua Portuguesa e o discurso da norma guesa em 1808, no Rio de Janeiro, que impulsionou o interesse pela escola e pela vida intelectual e artística. O Brasil do século XIX caracterizou-se por um espírito de época purista como forma de negar o atraso.

Alencar foi acusado de praticar uma linguagem descuidada, cheia de neologismos e galicismos. Dessa polêmica tomaram parte tanto portugueses quanto brasileiros contra Alencar. Em verdade, o centro das atenções era Portugale a produção linguística brasileira era toda voltada para lá e, portanto, o que escapasse à norma clássica portuguesa era duramente criticado. Diga-se, ainda, que os brasileiros eram mais rígidos que os próprios portugueses, pois queriam deixar patente sua erudição e provar não serem provincianos. (LEITE, 2006, p. 27, grifo nosso).

Somente a partir de 1922, com a Semana de Arte Moderna, o purismo, no Brasil, começou a se transformar em função de o movimento modernista apregoar a ruptura com o passado e uma reforma do panorama linguístico brasileiro por meio da defesa e da valorização da variedade linguística praticada aqui. A linguagem de Mário de Andrade, Manuel Bandeira, Carlos Drummond de Andrade, Guimarães Rosa, entre outros modernistas, permitiu que fosse praticada uma linguagem mais próxima da linguagem efetivamente em uso em nosso país, no entanto, os efeitos dessa abertura parecem não ter sido suficientes para romper com o conservadorismo da prescrição gramatical adotada no país. 
Heloisa Mara

Mendes

Maura de

Freitas Rocha

322

Os estudos linguísticos que investigam a sintaxe do português do Brasil, nos últimos anos, têm procurado descrever o processo de mudança linguística que o originou, bem como contrastá-lo com o português de Portugal. Grosso modo, esses estudos são contundentes quanto à distância entre um e outro e quanto à distância entre as formas linguísticas efetivamente em uso do português brasileiro e aquela que é prescrita nos manuais de gramática. Sobre essa distância, Pagotto (1998, p. 50, grifos nossos) afirma que

\footnotetext{
na relação do sujeito com a língua, a diversidade é normalmente sufocada pelo efeito simbólico que uma língua superior exerce sobre ele. As formas linguísticas da chamada norma culta estão impressas de sentidos que se ligam tanto à ancestralidade de uma cultura superior quanto à inscrição social do sujeito no domínio simbólico das diferenças. A relação com a norma culta tende para o eterno: ela é o sempre-lá, como se não tivesse origem histórica.
}

De acordo com Pagotto (1998), superado o período polêmico em torno da possível existência de uma "língua brasileira", a partir da segunda metade do século XIX, teve início a constituição de uma nova norma culta no Brasil que não se deu apenas por meio do registro de alguns usos das camadas mais escolarizadas da população, mas contou com um trabalho discursivo por parte de gramáticos, jornalistas e escritores na construção dos sentidos que, hoje, são atribuídos à escrita. Esse trabalho discursivo estava integrado a um modelo de sociedade baseado na manutenção da estrutura de dominação.

Com o intuito de observar de que modo a norma culta se comportava no período considerado o das grandes mudanças na sintaxe do português brasileiro, Pagotto compara a Constituição do Império, de 1824, e a Constituição da República, de 1892. Ele afirma que, de uma constituição para outra, algumas formas de escrita em desuso não foram substituídas por formas da modalidade oral do português brasileiro, mas por formas estranhas ao português falado no Brasil, o que acentuou ainda mais as diferenças entre fala e escrita no país. Essas diferenças são um importante indício de que, nesse período, a língua falada seguia um caminho, e a língua escrita caminhava na direção diametralmente oposta.

A não substituição de formas da escrita em desuso por formas presentes na fala dos brasileiros na passagem do Império para a Repúbli- 
ca pode ser exemplificada por meio do emprego dos clíticos. 0 estudioso verificou que a Constituição do Império apresenta casos severamente condenados pela atual norma culta, como empregar o clítico em início de sentença, em oposição ao uso enclítico presente na Constituição da República. Dados como esses permitiram ao pesquisador constatar que "os dois textos constitucionais foram escritos em gramáticas bastante diferentes uma da outra" (PAGOTTO, 1998, p. 52).

Para Pagotto (1998, p. 56), "o que chama a atenção no caso do Brasil é que todo um arsenal discursivo é acionado no sentido de "construir' a norma culta à imagem e semelhança do português de Portugal".

No campo literário, por exemplo, apesar da oposição de escritoO Museu da Língua Portuguesa e o discurso da norma res como José de Alencar à língua classicizante usada na literatura, havia um projeto político de nação e Estado que, ao mesmo tempo em que procurava romper politicamente com a antiga metrópole, também precisava se constituir à sua imagem e semelhança como forma de manter a oposição entre a elite e os demais segmentos da sociedade brasileira.

Afirmar o português do Brasil como gramática possível na língua escrita equivalia a nivelar por baixo, mesmo que uma série de traços da gramática já fizessem parte da fala daqueles que os queriam negar. Como o acesso a esta norma culta se daria somente a partir de rigorosa educação, estava garantido o processo de exclusão. (PAGOTTO, 1998, p. 57).

Para fazer essa afirmação, Pagotto baseia-se no historiador Antonio Gil (1994) para quem, na América Latina, a nacionalidade é estruturada a partir de um duplo enfoque: ao mesmo tempo em que a nação é vista como criação, o que pressupõe uma ruptura com o passado colonial, procura-se uma unidade cultural com esse passado, como forma de aproximar-se da civilização europeia. Sendo assim, de acordo com Gil (1994 apud PAGOTTO, 1998), as elites deveriam construir certa homogeneidade cultural que permitisse criar uma imagem social que lhe dava certa coesão.É nesse contexto, em que a elite busca aproximar-se da cultura europeia e, assim, se manter em oposição aos demais segmentos da população, que Pagotto localiza a constituição da norma culta brasileira no século XIX.

No campo científico, cujo discurso, para Pagotto (1998), foi o que mais contribuiu para a manutenção da norma purista tal como configurada no final do século XIX, gramáticas recentemente coloca- 
Heloisa Mara

Mendes

Maura de

Freitas Rocha

324

das no mercado também cumprem essa função, pois, buscando atualizar a descrição gramatical e romper com uma tradição pré-científica, se apropriam de certa Sociolinguística para justificar a norma culta. 0 argumento desses manuais é construído com base na adequação/inadequação dos usos linguísticos em contextos que não se igualam: são condescendentes com as situações comunicativas informais e inflexíveis nas situações que envolvem relações de poder.

Para Pagotto (1998), a norma culta no Brasil foi codificada à distância e à distância permanece. Se, no campo literário, durante o século XIX, determinadas formas linguísticas foram valorizadas com a finalidade de construir cuidadosamente uma identidade com o português de Portugal, no campo científico, a historicidade dessas formas está completamente apagada, o que, em alguma medida, justifica o fato de essa norma, ainda hoje, constar de gramáticas escolares, ser cobrada em boa parte dos exames de língua portuguesa e, mais recentemente, aparecer comentada e defendida em meios de comunicação de massa. A nosso ver, esse apagamento da historicidade das formas sustenta ad infinitum o efeito simbólico que a norma culta, tomada como "a" língua, exerce sobre o sujeito.

Como os estudos abordados evidenciam, a fixação de uma norma linguística, legitimada pelas gramáticas e dicionários, é uma forma de assegurar a coesão, a identidade e o poder de um grupo. Essa norma, definida como culta ou padrão, corresponde aos usos e atitudes linguísticas dos usuários que desfrutam de prestígio político, econômico e cultural dentro da nação, é transmitida pela escola e confundida com "a" língua.

Nos últimos anos, a norma culta codificada no século XIX é reproduzida, reafirmada e difundida nas gramáticas escolares, acompanhada de colunas em jornais e programas de televisão. Os estudos das especificidades do português brasileiro parecem não abalar o laborioso trabalho discursivo de manutenção da norma culta que, em 2006, parece ter ganhado um aparelho importante, o Museu da Língua Portuguesa.

\section{O discurso da norma no Museu da Língua Portuguesa}

Erros nossos de cada dia, instalação da exposição temporária Menas de que nos ocupamos aqui, é um painel de três metros de altura por doze metros de comprimento com ocorrências de usos da língua, seguidas de comentários que procuram mostrar que, por trás de cada um dos usos ou "erros", "há uma utilização criativa da língua, uma lógica interna das estruturas, uma analogia que os justifica" (MENAS..., 2010). 
O recorte dessa instalação justifica-se em função de que imagens e trechos do painel, à época da exposição, que ocorreu entre 15 de março e 27 de junho de 2010, foram amplamente divulgados como se ele desse o tom da mostra como um todo (o próprio título da exposição, Menas, foi retirado de um dos quadros do painel). Acrescenta-se a essa justificativa o título dado à instalação, sem que a palavras erros esteja grafada entre aspas, algo que parece "politicamente incorreto" a partir de uma abordagem sociolinguística, e a diversidade de fatos de linguagem que o museu classifica genericamente de "erros".

Adotamos para análise o conceito de língua como um conjunto de variedades. Nesse sentido, contrapomos norma padrão - representação ou imaginário linguístico inatingível - à realidade linguística e social, mais especificamente, à massa de variedades reais, concretas. O Museu da Língua Portuguesa e o discurso da norma Assumimos um continuum entre as variedades mais cultas, porque mais próximas do ideal de língua, e menos cultas porque mais distantes desse ideal, tanto em sua modalidade oral quanto escrita.

Ao assumirmos a noção de continuum entre as variedades do português, procuraremos mostrar que a dicotomia entre norma padrão ou culta e norma popular não é, a nosso ver, uma questão de fácil solução, pois, para levá-la a cabo, seria necessário reunir um conjunto de características linguísticas que permitisse diferenciá-las. Essa diferenciação, no português brasileiro, hoje, jamais seria uniforme. No entanto, parece-nos que o tratamento dispensado pelo museu aos fatos expostos em Erros nossos de cada dia obedece a essa dicotomia.

Há uma distância entre o modo como a instalação é apresentada e como ela é: os cem quadros que a compõem, como nossas análises procurarão evidenciar, não mostram o convívio entre a "língua padrão, aprendida na escola, e a língua familiar, aprendida em casa e nas ruas" (MENAS..., 2010, p. 27), como o texto de apresentação da instalação faz crer. Tampouco há, nos comentários de cada um dos quadros, a tentativa de mostrar que por trás de cada "utilização criativa da língua" existe uma "lógica das estruturas, uma analogia que as justifica" (MENAS..., 2010 , p. 27). Os comentários, em sua maioria, dispõem do discurso da norma e recorrem a aparelhos de referência, tal como os define Aléong (2001), para corrigir ou prescrever o emprego de uma forma e não de outra, com a alegação de que se trata de português culto, padrão.

Essas considerações nos levam a supor que o Museu da Língua Portuguesa, incontestavelmente um aparelho ideológico do Estado, de difu- 
são do discurso oficial sobre o português em nosso país, convoca, exibe o linguístico para o prescritivo funcionar; um linguístico depurado, um linguístico em conformidade com a grade de leitura da instituição.

Erros nossos de cada dia expõe três ocorrências de orações com relação às quais, os brasileiros, normalmente, eliminam a preposição:

Heloisa Mara Mendes

Maura de

Freitas Rocha

(1) Tenho medo que ocorra um terremoto aqui.

(2) As ideias que concordo são sempre as menos radicais.

(3) Eu gostaria que ela não viesse para cá.

Para essas três ocorrências, a exposição prescreve o emprego da forma descrita nos manuais de gramática normativa, ou seja, com a oração subordinada precedida de preposição. Não há qualquer tentativa de explicar a supressão da preposição. Nos quadros (1) e (2), a prescrição é ora relacionada à escrita, ora relacionada à fala. No quadro (3), há a ressalva de que "ao menos na língua formal" o complemento oracional de verbos regidos de preposição "deve vir" preposicionado. Que língua formal é essa?

Com relação, especificamente, às orações relativas, tal como exemplificado em (2) Tarallo (1983 apud RIBEIRO, 2002) descrevia como sendo, desde 1880, característico do português brasileiro o uso de relativas cortadoras, relativas lembrete (Conheço uma menina que ela só gosta de música clássica) e ausência de cujo (A casa que as janelas (dela) estão quebradas). Ribeiro (2002), por sua vez, afirma que essas construções são usadas frequentemente por universitários do curso de Letras sem que apresentem qualquer julgamento de estilos socialmente mais aceitos com relação a essas relativas. $\mathrm{Na}$ publicidade, a ocorrência de relativas cortadoras também é muito comum.

Acrescentamos que orações como (1), (2) e (3) são facilmente encontradas nas modalidades oral e escrita do português brasileiro atualmente, o que parece inviabilizar a manutenção da prescrição que toma corpo no museu.

De acordo com Galves (2001), o português do Brasil se diferencia do português de Portugal e das demais línguas latinas por ser uma língua de tópico. Grosso modo, a frase do português do Brasil teria a estrutura SN [SN V (SN)], diferentemente da frase do português de Portugal, cuja estrutura seria SN [V (SN)], o que equivale a enunciados como Maria, ela fez a comida, em que Maria é o tópico, ou seja, aquilo sobre o que 
se vai dizer alguma coisa, e Maria fez a comida, respectivamente. Para essa autora, a estrutura de tópico do português brasileiro é uma característica que explica vários aspectos particulares da nossa língua, entre eles, o uso do pronome ele como objeto, ele como sujeito, ele como objeto de preposição. Esse último aspecto está intimamente relacionado com o funcionamento das relativas.

Com relação ao uso do pronome ele como objeto, a mostra expõe uma ocorrência:

O Museu da Língua Portuguesa e o

(4) Eu vi ela na festa.

discurso da

norma

Como em todos os demais fatos linguísticos abordados na exposição, há a prescrição para que se "dê preferência, na língua escrita," aos pronomes oblíquos: "eu a vi na festa" ou "eu vi-a na festa". Apesar de frases como (4) serem muito comuns no Brasil, em Portugal essa é uma construção inexistente, o que nos leva a supor que o modelo de língua para o museu, ao prescrever o uso da forma canônica, é o da antiga metrópole.

O uso de ele como sujeito também é diferente no Brasil e em Portugal. Para Galves (2001), no português do Brasil, o ele como sujeito é a construção preferencialmente empregada, em detrimento das construções com sujeito nulo. Em Portugal, diferentemente, construções com sujeito nulo são mais frequentemente empregadas, e o ele como sujeito aparece quando é necessário marcar a concordância ou contraste. Enquanto no Brasil temos, por exemplo, eu tinha um vizinho que ele gostava de ouvir música alta, em Portugal, a ocorrência mais é comum é eu tinha um vizinho que gostava de ouvir música alta.

Em Erros nossos de cada dia, a construção com ele como sujeito, tal como a enumerada por Galves (2001), não é apresentada, mas há o registro de ele como sujeito ligado a uma preposição e o registro de mim como sujeito de verbo no infinitivo.

(5) o fato dele não saber inglês o incomoda.

(6) Isto é para mim fazer.

No primeiro caso, há a afirmação de que "sujeitos não são preposicionados", contrariando o uso efetivo da língua pelos brasileiros; e, no segundo, a de que "a língua escrita culta ainda preserva o pronome reto nessas frases: "para eu fazer"”. 


\author{
Heloisa Mara \\ Mendes \\ Maura de \\ Freitas Rocha \\ 328 \\ estigmatizado em nossa sociedade. As frases (8), (9), (10) e (11) são rea- \\ lizadas, de um modo geral, pela maioria dos brasileiros, não caracteri- \\ zando uma ou outra variedade: \\ (7) A gente vamos à escola todos os dias. \\ (8) Os padrões de previsão do tempo, devido ao aquecimento global, varia. \\ (9) Faltou as respostas mais interessantes. \\ (10) Tu sabe de uma coisa? \\ (11) Vende-se casas.
}

Outro fato morfossintático que dificulta definir características próprias à norma popular em oposição à norma culta, como parece pretender o Museu da Língua Portuguesa, diz respeito à concordância verbal. Partindo do que é exposto em Erros nossos de cada dia, apenas (7) permitiria a afirmação de que a ausência de concordância é característica das variedades populares, visto que se trata de um uso bastante

O comentário que acompanha (7) confunde variação com mudança no que diz respeito tanto ao emprego de pronomes sujeito quanto à concordância sujeito-verbo:

Os pronomes pessoais estão passando por grandes transformações no português brasileiro: você (em lugar de tu) a gente (em lugar de nós) são exemplos disso. Acontece que às vezes começamos a frase com um 'pronome novo', mas conjugamos o verbo como se ali ocorresse o 'pronome antigo'. Isso explica a frase abaixo [A gente vamos à escola todos os dias]. O português culto resiste a essas mudanças. Portanto, ainda se deve dizer: 'a gente foi à escola todos os dias'. (MENAS..., 2010, p. 30, grifos nossos).

O primeiro equívoco está relacionado à "transformação de tu em você e de nós em a gente". Não é necessário ser linguista para saber que as quatro formas coexistem e são de uso geral, com exceção do pronome tu que parece ter o uso mais concentrado no Rio Grande do Sul, no Rio do Janeiro e no Nordeste ${ }^{1}$. Em estudo realizado por Freitas, Franco e Cardoso (1986 apud RIBEIRO, 2002), foi observada uma variação na frequência de uso das formas nós e a gente, em falas cultas formais, mas a ausência to-

1 Enquanto tu sabe caracteriza o uso sulista do português brasileiro, a forma tu sabes ainda ocorre em algumas variantes regionais, como a de Maranhão, por exemplo. 
tal de a gente não foi registrada. O segundo equívoco refere-se ao fato de a alternância entre as formas pronominais justificar a ocorrência de (7). Acreditamos que seria mais apropriado falar, nesse caso, em hipercorreção, um esforço consciente para não "errar", para mostrar domínio das normas explícitas da língua. 0 terceiro remete à não diferenciação, por parte da mostra, entre variação e mudança. É prematuro afirmar que "a gente vamos" é uma mudança na língua. Esse tipo de afirmação pressupõe que todas as formas concorrentes (nós vamos, a gente vai, nóis vai) foram suplantadas. Seria mais prudente se a afirmação destacada na citação mencionasse a resistência a essa variante, uma forma entre tantas outras.

As frases (8) e (9) apresentam, respectivamente, distância entre O Museu da Língua Portuguesa e o discurso da norma o sujeito da oração e o verbo e posposição do sujeito ao verbo, aspectos que, no português brasileiro, contribuem para que a concordância entre o sujeito e o verbo no plural não se dê da forma como é prescrita. Ambos os casos são recorrentes na fala e na escrita dos brasileiros, inclusive de brasileiros com alto nível de escolarização, tal como exemplificado na citação abaixo:

\footnotetext{
No Brasil é também comum construções como 'está escrevendo', com estar + gerúndio, não comum em Portugal, onde se encontram expressões como 'está a escrever', com 'estar a + infinitivo'. (GUIMARÃES, 2005, p. 26, grifo nosso).
}

Com relação a (8), a interposição de "devido ao aquecimento globlal", ou seja, de palavras no singular, favorece a singularização do verbo. Fato semelhante, e igualmente recorrente nos usos efetivos que os brasileiros fazem da língua, ocorre quando há, entre o sujeito no singular e o verbo, a interposição de palavras no plural. Nesse caso, a pluralização do verbo é favorecida. Esse tipo de ocorrência está presente, também, na produção escrita de indivíduos altamente escolarizados, como a citação abaixo indicia:

\footnotetext{
Por outro lado, a pesquisa linguística levada a efeito por grandes projetos coletivos dos anos 70 confirmaram a hipótese de Nelson Rossi sobre o policentrismo da sociedade brasileira, nucleada - após a intensa urbanização do país - no Norte, Nordeste, Centro-Oeste, Sudeste e Sul (CASTILHO, [2009?], n.p., grifo nosso).
} 
Quando o enunciado está na forma canônica, ou seja, SV (sujeito-verbo), a não concordância verbal é cercada de reações preconceituosas dos falantes urbanos letrados. Diferentemente, um enunciado na ordem VS (verbo-sujeito), como (9), aparentemente, não sofre avaliações negativas e (ou) correções do lado de fora do Museu da Língua Portuguesa.

o comentário que acompanha o enunciado (8) é taxativo:

Heloisa Mara

Mendes

Maura de

Freitas Rocha

330

o núcleo do sujeito da oração é 'padrões', que está no plural. Portanto, o verbo deve estar no plural também: 'os padrões de previsão do tempo, devido ao aquecimento global, variam'. (MENAS..., 2010, p. 27).

O tom prescritivo, que predomina nos comentários, é amenizado com relação a (9). Após prescrever a "construção adequada ao padrão culto da língua", a recorrência de construções como (9) no português do Brasil é reconhecida: "É forte a tendência do português brasileiro a eliminar a concordância do verbo com o sujeito quando ele vem posposto, como no caso" (MENAS..., 2010, p. 30).

O enunciado (10) é exemplar de uma mudança em curso no português brasileiro, a redução das seis formas do verbo conjugado a apenas duas ou três: eu amo, tu/ele/a gente/vocês/eles ama ou eu amo, tu/ele/a gente ama, vocês/eles amam, sendo a primeira mais estigmatizada do que a segunda. A explicitação do sujeito pronominal parece tornar redundante o emprego das formas verbais com terminações número-pessoais ${ }^{2}$. Nas regiões em que o pronome pessoal tu é largamente empregado com a forma verbal da terceira pessoa do singular, seus usuários não sofrem qualquer sanção ou avaliação negativa.

Sobre enunciados como (11), em que há uma oração passiva sintética, por mais que os aparelhos de referência insistam no fato de que casas é o sujeito da oração e, portanto, o verbo "deve" concordar com o sujeito que está no plural, no uso, enunciados desse tipo são interpretados como tendo sujeito indeterminado e casas como complemento do verbo vender. Em Erros nossos de cada dia, a frequência cada vez maior de (11) é reconhecida, mas, em medida alguma, o comentário que acompanha o enunciado se desvencilha de seu caráter normativo:

2 A ocorrência frequente de sujeito explícito nas construções sintáticas é indicativa de outra mudança em curso no português brasileiro, a saber, a passagem de uma língua + pro drop para uma língua - pro drop, isto é, cujas sentenças requerem a presença de um pronome devido ao "esvaziamento" morfossintático das formas verbais, conforme apontam alguns pesquisadores brasileiros, entre eles, Galves (1984) e Duarte (1995). 
Embora essa construção ocorra com frequência cada vez maior no português contemporâneo, na linguagem culta escrita ainda é comum encontrar o verbo no plural: 'vendem-se casas' (ou seja, casas são vendidas). (MENAS..., 2010, p. 34).

Ao contrapor "português contemporâneo" à "linguagem culta escrita", no comentário reproduzido acima, há um efeito de sentido de que a forma "mais pura" do idioma estaria nos usos mais antigos e de que o uso atual não teria o valor "culto", tomado como intrínseco à escrita.

$O$ valor culto atribuído à escrita é recorrente em quadros sobre as realizações e colocações de complementos pronominais.

O Museu da Língua Portuguesa e o discurso da norma

De acordo com a mostra, são exemplos de colocação de complementos pronominais:

(12) Mandarei-te aquele e-mail amanhã pela manhã.

(13) Não lhe conheço.

Sobre (12), podemos afirmar que não se trata de um uso recorrente na fala e na escrita dos brasileiros, a não ser por hipercorreção.

A mesóclise com as formas de futuro, ‘Dir-te-ei uma coisa', está praticamente banida da fala brasileira [e também da escrita], ocorrendo ainda em algumas formas estereotipadas, clichês [ou em contexto escritos estritamente formais]. A forma em uso mesmo é 'Te direi uma coisa'o que conduz a uma segunda questão: uso do pronome em início de sentença, condenado pelos gramáticos, mas em realização frequente pelos brasileiros, independente do nível de escolarização. (RIBEIRO, 2002, p. 375).

O conservadorismo da mostra é tanto que, em (12), foi feita opção por uma forma não representativa do português brasileiro em função de uma norma gramatical, a que proíbe o uso de pronome em início de sentença. Realizações efetivas como te mandarei um e-mail amanhã não são um fato isolado, mas estão relacionadas ao abandono da ênclise no português brasileiro. Para Ribeiro (2002), a perda da mesóclise e a perda da ênclise não deixam outra opção estrutural para os brasileiros senão a de iniciar sentença com clítico, uma escolha que recobre variedades mais e menos padrão. 


\section{Heloisa Mara}

Mendes

Maura de

Freitas Rocha

$O$ uso de the como acusativo, tal como exemplificado em (13), ainda de acordo com Ribeiro (2002), é constante nas falas dos brasileiros, sem qualquer distinção entre falantes com níveis de escolarização diferentes. Em medida alguma, o comentário que acompanha (13) restringe-se a registrar usos linguísticos em situação de concorrência. O comentário é prescritivo e associa a escrita, como em exemplos anteriores, ao que é chamado de "padrão culto da língua". Novamente, a exposição trata como mudança aquilo que, no meio acadêmico, é definido como variação.

Com a mudança do quadro dos pronomes pessoais no português brasileiro, algumas formas estão desaparecendo, como $o, a$, sendo substituídos por lhe, como no caso abaixo [Não lhe conheço]. Na escrita, entretanto, prefira 'não o conheço', pois o pronome 'lhe' funciona, no padrão culto da língua, como objeto indireto e o verbo conhecer pede objeto direto. (MENAS..., 2010, p. 30).

Entre todas as ocorrências relacionadas a empregos de pronomes em Erros nossos de cada dia, cerca de dez quadros do painel, apenas duas podem ser consideradas como pertencentes a variedades menos prestigiadas:

(14) Eu estou fora de si.

(15) Vamos se ver amanhã?

Com relação à concordância nominal, dois quadros, especificamente, interessam para o que nos propomos, aqui:

(16) Quero duzentas gramas de presunto.

(17) Quebrei meu óculos.

Os enunciados (16) e (17) são acompanhados de comentários que preconizam "as formas corretas" no "padrão culto da língua", isto é, indicam que gramas pertence ao gênero masculino e que óculos é uma palavra sempre plural, respectivamente. A nosso ver, apenas (16) é representativo de uma variedade um pouco estigmatizada. Por sua vez, (17) recobre boa parte das variedades de prestígio, é de uso praticamente geral. Toda a manobra para difusão e imposição do emprego 
de óculos como um substantivo masculino plural, por parte dos aparelhos de referência, é insuficiente, visto que, semanticamente, óculos denota um objeto unitário, sendo assim, se o objeto é considerado como uma unidade, a lógica linguística dos falantes designa que ele só pode ser referido no singular.

Outros enunciados expostos na mostra sem que fosse considerada a lógica linguística dos brasileiros dizem respeito ao emprego do pronome indefinido menos e do advérbio meio.

O Museu da Língua Portuguesa e o discurso da norma

Obviamente, os comentários que acompanham (18) e (19) fazem remissão ao "padrão culto da língua" e à invariabilidade das palavras pertencentes à classe dos pronomes indefinidos e dos advérbios. Nesses comentários, não há qualquer menção ao fato de que palavras da mesma classe gramatical podem apresentar comportamentos sintáticos diferentes.

O enunciado (18), especificamente, dá nome à exposição temporária, Menas o certo do errado, o errado do certo. Um nome bastante infeliz, visto que as realizações reais de menas só ocorrem diante de substantivos de gênero feminino. Nesse sentido, a mostra e, por extensão, o museu erram (sem aspas) por veicularem algo que, por ora, não configura um uso linguístico efetivo por parte dos brasileiros.

Questões de regência e flexão verbais também ocupam parte dos quadros do painel. Para o museu, "modernamente", os brasileiros falam (20), mas não o escrevem.

(20) Vamos no jogo amanhã?

Em uma rápida pesquisa em um site de buscas, restrita a páginas do Brasil, foram encontradas 5.710 .000 ocorrências para o parâmetro "vamos ao" contra 7.890.000 para o parâmetro "vamos no", o que, de alguma maneira, assegura a coexistência de ambas as formas na escrita.

No comentário a (20), há a indicação de que "a preposição $a$ indica com mais clareza o ponto para o qual nos deslocamos" (MENAS..., 2010, p. 30). Acreditamos que se essa preposição fosse, efetivamente, mais clara, ela não seria preterida pelos usuários de algumas variedades do português do Brasil. 
Os enunciados sobre flexão verbal também oscilam entre formas mais estigmatizadas, como (21), menos estigmatizadas, tal como exemplificadas em (22), e formas totalmente aceitas na variedade mais próxima da norma padrão, exemplificadas em (23).

\section{Heloisa Mara} Mendes

Maura de

Freitas Rocha

(21) Espero que seje bom pra você.

(22) Ele vai vim para a exposição.

(23) Eu explodo de raiva.

O tratamento conferido aos usos de (21) e (22) reafirmam seu não pertencimento à "norma culta". Quanto a (23), reproduzimos o comentário abaixo.

Muitos gramáticos e dicionaristas consideram que 'explodir' é verbo defectivo, que, como tal, não deve ser usado na primeira pessoa do singular do presente do indicativo. Para eles, numa situação como essa, o ideal - no padrão culto da língua - seria dizer algo como 'eu estou explodindo de raiva'. Mostrando que a língua muda, o Houaiss e outros gramáticos já admitem a forma 'explodo'. (MENAS..., 2010, p. 33, grifos nossos).

O Museu da Língua Portuguesa parece querer se eximir de qualquer responsabilidade pela prescrição ou não de explodo. 0 ponto de vista de "muitos gramáticos e dicionaristas" é apresentado e ocupa dois terços da extensão do comentário. Em seguida, para mostrar que a língua muda, afirma-se que Houaiss e outros gramáticos admitem a forma explodo. Apenas aparentemente o museu se exime da responsabilidade, visto que (23) pertence a um conjunto de ocorrências linguísticas denominadas como "erros".

Na fala, não há “erro", há variação. Na escrita, a variação é resultado da incorporação de ocorrências da fala. Em nossas análises, consideramos que os enunciados analisados até aqui ocorrem tanto na fala quanto na escrita dos brasileiros. Para esses enunciados, pode-se falar em variação linguística. Nos enunciados restritos à escrita que apresentamos a seguir, não se pode falar em variação, visto que as variações da representação escrita, decorrentes de variações fonético-fonológicas, são registradas nos dicionários como formas pertencentes às variantes oficiais, as quais não têm lugar na instalação em questão.

No painel, as ocorrências que remetem a questões exclusivas da modalidade escrita da língua são maioria, cerca de quarenta e quatro dos 
cem quadros. Como elas não configuram um aspecto de variação linguística propriamente dita do português do Brasil, vamos apresentá-las brevemente com o intuito de reforçar nossa hipótese de que a representação que o museu faz do que seja variação é equivocada, visto que ocorrências de naturezas muito diversas são classificadas genericamente de "erros", além do fato de a instituição tomar como língua a modalidade escrita da língua.

Os quadros que exploram questões ortográficas podem ser separados em três grupos: o primeiro grupo explora homônimos heterógrafos e parônimos; o segundo grupo aborda o emprego da crase; e o terceiro grupo, desvios das normas ortográficas, sendo, alguns deles, caracterizadores de uma variante oral estigmatizada.

São pertencentes ao primeiro grupo frases como:

O Museu da

Língua Por-

tuguesa e o

discurso da

norma

(24) A liminar foi caçada pela desembargadora.

(25) Ninguém tem o direito de me taxar de corrupto.

Os comentários que acompanham esses enunciados apresentam o par de palavras e seus respectivos significados. Em função dos limites deste trabalho, citaremos um deles como forma de exemplificar.

Caçar e cassar são homônimos, mantendo sentidos diferentes. Caçar é 'sair à caça', e a desembargadora não deve ter abatido a liminar a tiros. Cassar é 'suspender os efeitos de uma ação'. Nossa desembargadora foi por aqui: 'a liminar foi cassada pela desembargadora'. (MENAS..., 2010, p. 27).

Entre os quadros que recobrem inadequações quanto ao emprego da crase, recortamos:

(26) À partir de maio, volta a fazer frio.

(27) De segunda à sábado, suculenta feijoada.

(28) Tudo na loja era vendido à prazo.

Nessas frases, os comentários que as acompanham reiteram a regra para o emprego da crase e apresentam a forma adequada de acordo com a ortografia da língua portuguesa.

Os enunciados de (29) a (31) são alguns exemplos do terceiro grupo. 
(29) Não se esqueça de incluir a data no cabeçário da prova.

(30) Aja paciência para tantas exceções!

(31) É preciso colocar fim aos previlégios.

É conveniente destacar que, assim como a representação de língua adotada pelo Museu da Língua Portuguesa em Erros nossos de cada dia é

Heloisa Mara

Mendes

Maura de

Freitas Rocha

336 idealizada, como se a língua fosse, de fato, o conjunto das normas reunidas nas gramáticas normativas e não o conjunto dos comportamentos linguísticos de seus usuários, a representação que a instituição faz de variante popular tampouco se aproxima das realizações reais. Parecem-nos inconsistentes fatos como um indivíduo trocar cabeçalho por cabecário e empregar o verbo esquecer de acordo com sua regência mais tradicional, tal como exemplificado em (29); enganar-se com relação à grafia do verbo haver no presente do subjuntivo, mas não com relação à grafia de exceções, como em (30); ou ainda, escrever/ dizer (31), mas não colocar fim nos previlégios.

Em conformidade com o que afirmamos anteriormente, as frases reunidas no grupo três apresentam questões restritas à ortografia, mas, entre elas, há palavras que, quando são ditas, caracterizam, mesmo que minimamente, uma variante estigmatizada. Essas palavras são encontradas em (29) e (31).

\section{Considerações finais}

Como nossas análises procuraram mostrar, em Erros nossos de cada dia, há a reiteração de um discurso da norma que procura manter uma situação de dominação daquilo que se convencionou chamar de norma culta no Brasil, foi codificada nos manuais de gramática normativa e dicionários no século XIX e é confundida com "a" língua.

A instalação apresenta uma série de equívocos. Reúne sob a definição genérica de "erros" uma série de usos linguísticos de diferentes ordens, define como mudança aspectos ligados à variação linguística, é incapaz de discernir o que é marcado do que é não marcado no português do Brasil, assume uma definição de língua como um conjunto de normas, apresenta construções que sequer constituem exemplos dos usos efetivos que os brasileiros fazem da língua e comentários que não se limitam a reconhecer que há construções sintáticas em situação de concorrência no português brasileiro, mas são prescritivos.

Além disso, por meio dos comentários que acompanham os "erros", há um tom de "desdém" e de "menosprezo" com relação a formas 
que a exposição trata como não sendo pertencentes à norma culta. Isso se dá, por exemplo, pela insistência no fato de que elas são encontradas na "linguagem coloquial", "familiar" ou "popular", denominações que, em alguma medida, situam essas formas às margens daquilo que a exposição e, por extensão o museu, concebem como língua.

A partir da análise dessa instalação, acreditamos que é possível assumir que o Museu da Língua Portuguesa é mais um aparelho de difusão e imposição da norma padrão em nosso país, assim como a escola, as colunas de jornal, os manuais de redação e a Academia Brasileira de Letras. Diferentemente dos demais aparelhos, o museu procura parecer mais "democrático" no tratamento dos fatos linguísticos na medida em que expõe questões relacionadas à variação e tenta incorporar uma multiplicidade de vozes sobre língua, apesar de fazê-lo

O Museu da Língua Portuguesa e o discurso da norma

\section{Referências}

ALÉONG, Stanley. Normas linguísticas, normas sociais: uma perspectiva antropológica. In: BAGNO, Marcos. (Org.). Norma linguística. São Paulo: Loyola, 2001. p. 145-174.

ALKMIM, Tânia. Sociolinguística. In: MUSSALIM, Fernanda; BENTES, Anna Christina. (Org.). Introdução à linguística: domínios e fronteiras. São Paulo: Cortez, 2001. v. 1, p. 21-47.

CASTILHO, Ataliba Teixeira de. Variação linguística, norma culta e ensino da língua materna. In: BRASIL. Subsídios à proposta curricular em língua portuguesa para $1^{\circ}$ e $2^{\circ}$ graus. São Paulo: SE/ CENP, 1988. v. 3, p. 53-59.

A hora e a vez do português brasileiro. [2009?]. Disponível em: <http://www.museulinguaportuguesa.org.br/colunas.php>. Acesso em: 20 jan. 2012. 
DUARTE, Maria Eugênia Lamoglia. A perda do princípio "Evite Pronome" no português brasileiro. 1995. $141 \mathrm{f}$. Tese (Doutorado em Ciências da Linguagem)-Universidade Estadual de Campinas, Campinas, 1995.

GALVES, Charlote. Pronomes e categorias vazias em português do

Heloisa Mara Mendes

Maura de Freitas Rocha Brasil. Cadernos de Estudos Linguísticos, Campinas, n. 7, p. 107136, 1984.

. Ensaios sobre as gramáticas do português. Campinas: Ed. da Unicamp, 2001.

GNERRE, Maurízio. Linguagem, poder e discriminação. In: Linguagem, escrita e poder. São Paulo: Martins Fontes, 1998. p. 5-34.

GUIMARÃES, Eduardo. A língua portuguesa no Brasil. Ciência e Cultura, São Paulo, v. 57, n. 2, p. 24-28, abr./jun. 2005. Disponível em: <http://cienciaecultura.bvs.br/scielo.php?pid=S0009$-67252005000200015 \&$ script=sci_arttext>. Acesso em: 20 jan. 2012.

LEITE, Marli Quadros. Metalinguagem e discurso: a configuração do purismo brasileiro. 2. ed. São Paulo: Humanitas, 2006.

MENAS O CERTO DO ERRADO, O ERRADO DO CERTO. São Paulo: Museu da Língua Portuguesa, 2010. 96 p. (Catálogo da exposição realizada no Museu da Língua Portuguesa, de 15 de março a 27 de junho de 2010).

PAGOTTO, Emilio Gozze. Norma e condescendência: ciência e pureza. Línguas e Instrumentos Linguísticos, Campinas, n. 2, p. 49-68, 1998.

RIBEIRO, Ilza. Quais as faces do português culto brasileiro? In: ALKMIM, Tânia Maria (Org.). Para a história do português brasileiro. São Paulo: Humanitas FFLCH/USP, 2002. p. 359-381. 